\title{
Analisis Fatigue Life pada Bracket Oil Tanker dengan Beban Sloshing
}

\author{
Muhamad Gifari Rusdi, M. Nurul Misbah, dan Totok Yulianto \\ Departemen Teknik Perkapalan, Fakultas Teknologi Kelautan, Institut Teknologi Sepuluh Nopember (ITS) \\ e-mail:mnmisbah@na.its.ac.id
}

\begin{abstract}
Abstrak-Umur kelelahan (fatigue life) dari struktur kapal tanker dapat dianalisis dengan menggunakan pendekatanpendekatan standar pada Common Structural Rules for Double Hull Oil Tanker. Analisis dilakukan dengan metode elemen hingga yang difokuskan pada konstruksi bracket kapal tanker 17500 LTDW. Konstruksi bracket merupakan salah satu penopang yang esensial pada kapal sehingga perlu diketahui letak bracket dengan tegangan paling besar untuk dihitung nilai umur kelelahannya. Kapal ini dimodelkan dengan menggunakan finite element software. Bagian yang dimodelkan adalah tiga ruang muat di midship. Fatigue life yang dianalisa merupakan pengaruh dari beban sloshing muatan tangki (beban internal). Kondisi pembebanan dilakukan pada 4 macam tinggi pengisian muatan yaitu ketinggian $0.3 \mathrm{~h}, 0.6 \mathrm{~h}, 0.7 \mathrm{~h}$, dan $0.95 \mathrm{~h}$, dan masingmasing kondisi mempunyai variasi dari roll angle motion yang dihitung sesuai persamaan-persamaan dalam CSR. Tegangan pada bracket diambil dari salah satu web frame yang mempunyai tegangan terbesar di setiap kondisi pembebanannya untuk dianalisa fatigue lifenya. Hasil menunjukkan bahwa bracket dengan tegangan paling besar terjadi pada sambungan bracket pada web frame nomor 4 pada ruang muat belakang. Umur kelelahan pada masing-masing kondisi adalah 450 tahun pada Kondisi 1 (0.3h), 84 tahun pada Kondisi $2(0.6 h), 76$ tahun pada Kondisi 3 (0.7h), dan 137 tahun pada Kondisi 4 (0.95h). Umur kelelahan paling rendah terdapat pada kondisi pembebanan 3 dengan tinggi muatan $0.7 \mathrm{~h}$ yaitu sebesar 76 tahun.
\end{abstract}

Kata Kunci-CSR, bracket, analisa tegangan, fatigue life.

\section{PENDAHULUAN}

$\mathrm{T}$ EKNOLOGI eksplorasi dan eksploitasi minyak semakin meningkat seiring dengan meningkatnya kebutuhan minyak yang berdampak pada semakin pesatnya pencarian sumber minyak di laut dalam. Oleh karena itu dibutuhkan kapal - kapal pengangkut minyak baik mentah maupun produk dari drilling site atau extraction point ke tempat penyulingan atau daratan. Salah satunya, yakni dengan menggunakan oil tanker.

Agar dapat bertahan selama masa operasinya, suatu struktur konstruksi didesain untuk mampu bertahan dari berbagai beban kerja yang dialaminya. Secara prinsip, selama beban kerja yang dialami tidak melewati batas maksimum yang ditentukan maka kegagalan struktur tidak akan terjadi. Namun apabila beban tersebut diberikan berulang-ulang secara terusmenerus, walaupun beban yang diberikan berada di bawah batas maksimum desain, maka perhatian khusus perlu diberikan.

Untuk menghindari kegagalan akibat kelelahan selama masa pengoperasian suatu struktur maka perlu dilakukan analisa kelelahan (fatigue). Pada studi ini, fokus analisis dilakukan pada konstruksi bracket karena bracket dianggap sebagai salah satu penopang yang esensial. Oleh karena itu, perlu diketahui letak bracket dengan tegangan paling besar dan besar fatigue lifenya. Nilai tegangan akan diperoleh berdasarkan analisa tegangan yang dilakukan dengan metode numerik elemen hingga.

Regulasi yang akan dipakai sebagai acuan adalah Common Structural Rules for Double Hull Oil Tanker (2014). Pada CSR dijabarkan cukup jelas dan lengkap mengenai aturan-aturan tentang perhitungan fatigue.

\section{TINJAUAN PUSTAKA}

\section{A. Analisis Kelelahan}

Kelelahan (fatigue) sangat mempengaruhi retak (crack) yang terjadi pada struktur detail sambungan [1]. kelelahan (fatigue) telah menjadi hal yang dipertimbangkan dalam kekuatan kapal yang sudah beroperasi lama maupun kapal yang baru beroperasi. Dalam penelitian sebelumnya, Kurnianto [2] telah melakukan penelitian tentang perkiraan umur konstruksi FPSO konversi dari tanker dengan analisis fatigue dengan dua metode yaitu deterministic dan simplified. Hasil menunjukkan bahwa metode simplified lebih akurat. Metode simplified adalah metode perhitungan fatigue dengan mempertimbangkan probabilitas dari kejadian gelombang yang terdistribusi secara acak, dengan adanya faktor Weibull Shape Parameter. Faktor weibull digunakan dalam perhitungan fatigue menurut $C S R$.

Septiana [3] telah melakukan perhitungan perkiraan fatigue life dari bracket kapal tanker berdasarkan Common Structural Rules for Double Hull Oil Tanker. Kapal tersebut merupakan kapal tanker single hull yang dihitung umur kelelahan bracketnya mengguanakan beban statis dan dinamis akibat muatan tangki dan gelombang. Oleh karena itu, dalam penelitian ini digunakan beban yang berbeda yaitu beban sloshing tangki dengan persamaan pendekatan berdasarkan Common Structural Rules for Double Hull Oil Tanker (2014).

Anwar [4] telah melakukan analisa sloshing pada tangki LNG akibat pengaruh gerakan heaving dan pitching kapal pada gelombang reguler. Analisa dilakukan dengan menggukanan frekuensi sloshing yang sama dengan frekuensi gerakan kapal pada kondisi heaving dan pitching secara bersamaan (coupled). Sehingga dapat ditentukan lokasi tekanan terbesar yang terjadi dalam dinding tangki membran 
kapal LNG pada ketinggian cairan 30\%, 50\%, dan $80 \%$ tinggi tangki. Oleh karena itu, pada penelitian ini digunakan asumsi frekuensi sloshing adalah sama dengan frekuensi gerakan kapal tanpa melibatkan beban dinamis gelombang.

\section{B. Faktor Korosi}

Tebal pelat yang ada pada struktur harus ditambahkan faktor korosi. Penambahan faktor korosi berbeda pada tiaptiap bagian karena beban yang diterima berbeda. Perhitungan menggunakan tebal aktual ditambahkan $-0.5 \mathrm{t}_{\text {corr }}$.

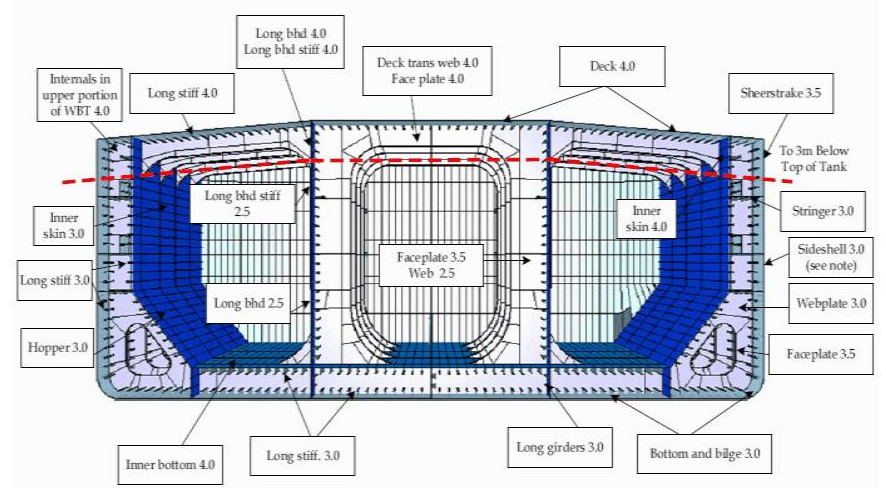

Gambar 1. Corrossion Addition (CSR, 2014)

\section{C.Pembebanan}

Menurut CSR [5], beban dibagi menjadi 4 macam, yaitu beban statis, beban dinamis, beban sloshing, dan beban impact. Namun dalam penelitian ini hanya menggunakan beban sloshing muatan dengan variasi tinggi muatan dan pengaruh akibat gerak rolling kapal tanpa melibatkan beban dinamis gelombang air laut.

1) Beban Sloshing

$$
P_{\text {sllh }-t}=7 \rho g f_{\text {sll }}\left(\frac{b_{\text {sllh }}}{B}-0.3\right) G M^{0.75} \quad \mathrm{kN} / \mathrm{m}^{2}
$$

$P_{\text {slh-t }}$ adalah beban sloshing tangki dalam $\mathrm{kN} / \mathrm{m}^{2}$

\section{2) Roll Motion}

$U_{\text {roll }}=\frac{2.30 r_{\text {roll }- \text { gyr }}}{\sqrt{G M}} \quad$ secs

$U_{\text {roll }}$ adalah natural roll period dalam detik (secs)

$$
\theta=\frac{50}{B+75}\left(1.25-0.025 U_{\text {roll }}\right) f_{b k} \quad \text { rads }
$$

$\theta$ adalah sudut dari natural roll period dengan satuan radian (rad).

Beban sloshing akibat gerakan muatan searah melintang merupakan nilai yang konstan untuk tiap tinggi pengisian muatan dimulai dari 0.05 hmax sampai 0.95 hmax dengan kenaikan setiap 0.05 hmax. Dalam studi ini variasi kondisi tinggi pengisian muatan yang digunakan dibagi menjadi 4 kondisi pembebanan yaitu, $0.3 \mathrm{~h}, 0.6 \mathrm{~h}, 0.7 \mathrm{~h}$, dan $0.95 \mathrm{~h}$. Sedangkan untuk sudut roll $\theta$ (roll angle) dari natural roll period kapal yang digunakan adalah $30^{\circ}$.

\section{Kurva $S-N$}

Hubungan antara rentang tegangan dan jumlah kejadian (cycle) untuk mengalami kegagalan struktur adalah fungsi dari tipe sambungan, lingkungan, dan ketebalan pelat. Untuk analisis kelelahan berdasarkan pendekatan tegangan nominal, sambungan las dibagi menjadi beberapa klas. Tiap klas memiliki desain kurva S-N yang berbeda. Pada struktur sambungan las, S-N diagram merupakan cara paling umum yang digunakan dalam menentukan kapasitas kelelahan. S-N diagram menunjukan hubungan antara rentang tegangan $(\mathrm{S})$ dari tegangan nominal terhadap jumlah siklus yang dialami untuk mecapai kegagalannya $(\mathrm{N})$. Jumlah siklus kegagalan diperoleh berdasarkan pengujian beban amplitudo konstan terhadap material yang diujikan hingga terjadi kegagalan [6].

Kekuatan sambungan las dengan kekuatan kelelahan dicirikan dengan kurva $\mathrm{S}-\mathrm{N}$ yang memberikan hubungan rentang tegangan yang terjadi pada suatu detil struktur dan jumlah siklus beban amplitudo konstan untuk kegagalan.

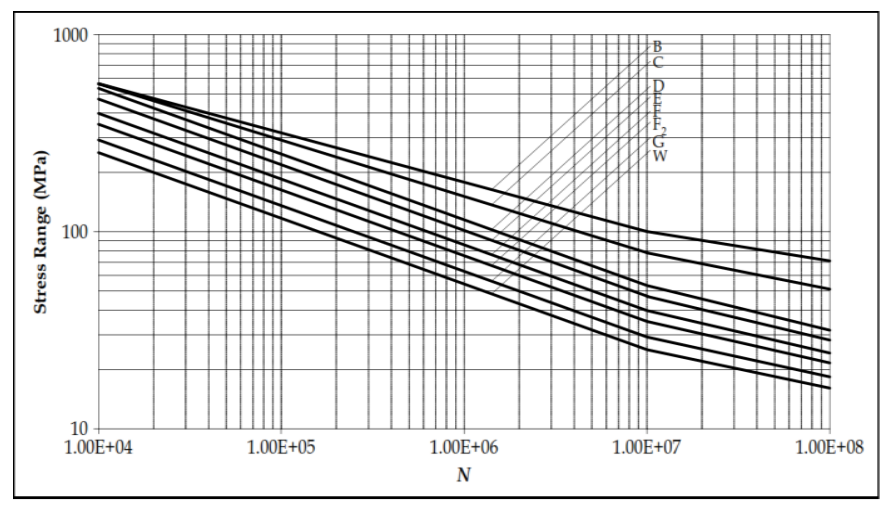

Gambar 1. Kurva S-N Sambungan Las

\section{METEDOLOGI PENELITIAN}

\section{A. Pengumpulan Data}

Pengumpulan data bertujuan untuk memperoleh data primer dan/atau data sekunder yang berkaitan dengan kasus yang akan dikaji dalam studi ini. Kapal yang digunakan sebagai kajian dalam studi ini adalah kapal Tanker Double Hull 17.500 LTDW. Data ukuran utama kapal tersebut ditunjukkan pada Tabel 1.

Tabel 1.

Ukuran Utama Kapal Tanker 17500 LTDW

\begin{tabular}{lll}
\hline \multicolumn{1}{c}{ Description } & & \multicolumn{2}{c}{ Quantity } \\
\hline Displacement & $(\Delta)$ & $17500 \mathrm{Ton}$ \\
Length Overall & $\left(\mathrm{L}_{\mathrm{OA}}\right)$ & $157.50 \mathrm{~m}$ \\
Length Perpendicular & $\left(\mathrm{L}_{\mathrm{PP}}\right)$ & $149.50 \mathrm{~m}$ \\
Breadth Moulded & $(\mathrm{B})$ & $27.70 \mathrm{~m}$ \\
Depth & $(\mathrm{D})$ & $12.00 \mathrm{~m}$ \\
Draft & $(\mathrm{T})$ & $7.00 \mathrm{~m}$ \\
Service Speed & $\left(\mathrm{V}_{\mathrm{S}}\right)$ & $13.0 \mathrm{Knots}$ \\
\hline \hline
\end{tabular}

\section{B. Pemodelan}

Pada penelitian ini dilakukan pemodelan pada 3 ruang muat di daerah midship dengan menggunakan finite element software. Setelah dibuat 3 ruang muat, material properties 
dimasukkan pada model (tebal pelat, ukuran profil, modulus elastisitas, jenis baja). Kemudian dilakukan pembuatan model yang meliputi:
1) Keypoint
2) Line
3) Area
4) Meshing
5) Kondisi batas

Setelah model selesai, kemudian dilakukan perhitungan tegangan akibat beban yang diinputkan pada model.

\section{Perhitungan Kelelahan}

Perhitungan fatigue dari struktur kapal tanker ini berdasarkan penerapan aturan Palmgren-Miner Cumulative Damage dimana ketika fatigue damage ratio, DM memiliki nilai lebih dari 1 maka dapat dipastikan bahwa struktur tersebut tidak diterima atau mengalami kegagalan. Perhitungan cumulative fatigue damage dilakukan untuk mengetahui besar akumulasi kerusakan kelelahan akibat masing-masing kondisi pembebanan.

Dihitung $\mathrm{DM}_{\mathrm{i}}$ untuk tiap kondisi pembebanan baik tanpa rolling maupun dengan rolling. Setelah itu menjumlahkan keseluruhan cumulative fatigue damage DM yang timbul. Kemudian umur kelelahan dari suatu struktur sambungan lasan pada bracket dapat dihitung nilainya.

\section{ANALISIS DAN PEMBAHASAN}

\section{A. Kondisi Pembebanan 1}

Kondisi Pembebanan 1 adalah input beban pada model dengan tinggi pengisian muatan $0.3 \mathrm{~h}$ serta variasi sudut roll $30^{\circ}$ kiri dan kanan. Hasil tegangan kondisi pembebanan 1 ditunjukkan pada Tabel 2.

Tabel 2.

Hasil Tegangan Kondisi Pembebanan 1

\begin{tabular}{cccc}
\hline \hline $\begin{array}{c}\text { Kondisi } \\
\text { muatan }\end{array}$ & Sambungan & Frame & $\begin{array}{c}\sigma \mathrm{MAX} \\
\left(\mathrm{N} / \mathrm{mm}^{2}\right)\end{array}$ \\
\hline $\begin{array}{c}\text { tanpa roll angle } \\
\text { roll angle } \theta 30^{\circ}\end{array}$ & $\begin{array}{c}\text { bracket dengan } \\
\text { web frame } \\
\text { kriri } \\
\text { kracket dengan } \\
\text { web frame }\end{array}$ & 4 & 35.1 \\
$\begin{array}{c}\text { roll angle } \theta 30^{\circ} \\
\text { kanan }\end{array}$ & $\begin{array}{c}\text { bracket dengan } \\
\text { web frame }\end{array}$ & 4 & 33.7 \\
\hline \hline
\end{tabular}

\section{B. Kondisi Pembebanan 2}

Kondisi Pembebanan 2 adalah input beban pada model dengan tinggi pengisian muatan $0.6 \mathrm{~h}$ serta variasi sudut roll $30^{\circ}$ kiri dan kanan. Hasil tegangan kondisi pembebanan 2 ditunjukkan pada Tabel 3.

Tabel 3.

Hasil Tegangan Kondisi Pembebanan 2

\begin{tabular}{|c|c|c|c|}
\hline $\begin{array}{l}\text { Kondisi } \\
\text { muatan }\end{array}$ & Sambungan & Frame & $\begin{array}{l}\sigma \mathrm{MAX} \\
\left(\mathrm{N} / \mathrm{mm}^{2}\right) \\
\end{array}$ \\
\hline tanpa roll angle & $\begin{array}{l}\text { bracket dengan } \\
\text { web frame }\end{array}$ & 4 & 50 \\
\hline $\begin{array}{c}\text { roll angle } \\
\text { kiri }\end{array}$ & $\begin{array}{l}\text { bracket dengan } \\
\text { web frame }\end{array}$ & 4 & 49.8 \\
\hline $\begin{array}{l}\text { roll angle } \theta 30^{\circ} \\
\text { kanan }\end{array}$ & $\begin{array}{c}\text { bracket dengan } \\
\text { web frame }\end{array}$ & 4 & 50.5 \\
\hline
\end{tabular}

\section{Kondisi Pembebanan 3}

Kondisi Pembebanan 3 adalah input beban pada model dengan tinggi pengisian muatan $0.7 \mathrm{~h}$ serta variasi sudut roll $30^{\circ}$ kiri dan kanan. Hasil tegangan kondisi pembebanan 3 ditunjukkan pada Tabel 4.

Tabel 4.

Hasil Tegangan Kondisi Pembebanan 3

\begin{tabular}{|c|c|c|c|}
\hline $\begin{array}{l}\text { Kondisi } \\
\text { muatan }\end{array}$ & Sambungan & Frame & $\begin{array}{c}\sigma \mathrm{MAX} \\
\left(\mathrm{N} / \mathrm{mm}^{2}\right)\end{array}$ \\
\hline tanpa roll angle & $\begin{array}{l}\text { bracket dengan } \\
\text { web frame }\end{array}$ & 4 & 50.8 \\
\hline $\begin{array}{c}\text { roll angle } \theta 30^{\circ} \\
\text { kiri }\end{array}$ & $\begin{array}{l}\text { bracket dengan } \\
\text { web frame }\end{array}$ & 4 & 51.4 \\
\hline $\begin{array}{c}\text { roll angle } \theta 30^{\circ} \\
\text { kanan }\end{array}$ & $\begin{array}{c}\text { bracket dengan } \\
\text { web frame }\end{array}$ & 4 & 52 \\
\hline
\end{tabular}

\section{Kondisi Pembebanan 4}

Kondisi Pembebanan 4 adalah input beban pada model dengan tinggi pengisian muatan $0.95 \mathrm{~h}$ serta variasi sudut roll $30^{\circ}$ kiri dan kanan. Hasil tegangan kondisi pembebanan 4 ditunjukkan pada Tabel 5.

Tabel 5.

Hasil Tegangan Kondisi Pembebanan 4

\begin{tabular}{cccc}
\hline \hline $\begin{array}{c}\text { Kondisi } \\
\text { muatan }\end{array}$ & Sambungan & Frame & $\begin{array}{c}\sigma \mathrm{MAX} \\
\left(\mathrm{N} / \mathrm{mm}^{2}\right)\end{array}$ \\
\hline $\begin{array}{c}\text { bracket } \text { dengan } \\
\text { web frame }\end{array}$ & 4 & 44.3 \\
roll angle $\theta 30^{\circ}$ & $\begin{array}{c}\text { bracket } \text { dengan } \\
\text { keb frame }\end{array}$ & 4 & 45.2 \\
$\begin{array}{c}\text { kiri } \\
\text { roll angle } \theta 30^{\circ} \\
\text { kanan }\end{array}$ & $\begin{array}{c}\text { bracket dengan } \\
\text { web frame }\end{array}$ & 4 & 44.4 \\
\hline \hline
\end{tabular}

\section{E. Faktor Konsentrasi Tegangan}

Faktor konsentrasi tegangan terjadi pada detil struktur akibat adanya diskontinuitas seperti lubang atau retakan. Semua faktor konsentrasi tegangan yang berpengaruh pada kondisi sambungan harus diperhatikan dan dimasukkan ke dalam perhitungan. Faktor-faktor konsentrasi tegangan seperti $\mathrm{K}_{\mathrm{gl}}, \quad \mathrm{K}_{\mathrm{gh}}, \mathrm{K}_{\mathrm{df}}$, serta $\mathrm{K}_{\mathrm{dA}}$ harus diperhitungkan untuk menentukan nilai faktor konsentrasi tegangan total $\mathrm{K}$.

Untuk mendapatkan rentang tegangan yang digunakan dalam menghitung cumulative fatigue damage, maka tegangan maksimum pada sambungan pada semua kondisi pembebanan harus dikalikan dengan faktor konsentrasi tegangan $\mathrm{K}$ sesuai dengan Tabel 6. sehingga akan didapatkan rentang tegangan $\mathrm{S}_{\mathrm{Ri}}$.

Tabel 6.

Faktor Konsentrasi Tegangan

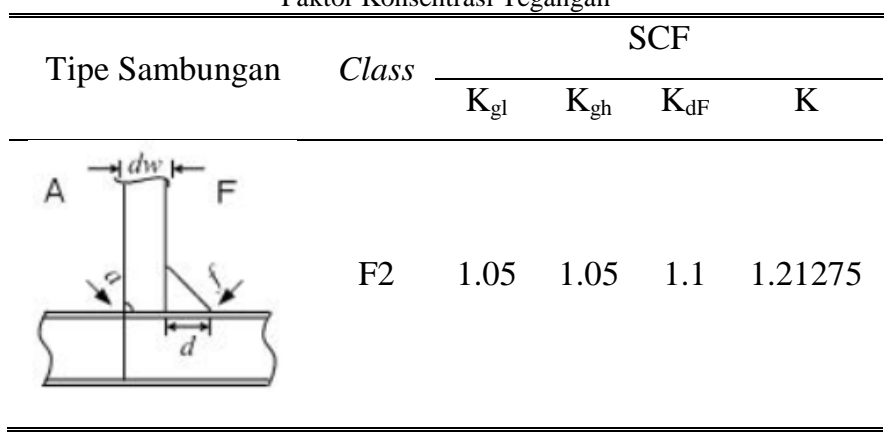




\section{F. Kurva $S-N$}

Berdasarkan kurva S-N yang terdapat dalam Common Structural Rules for Double Hull Oil Tanker, nilai $\mathrm{K}_{2}$ bergantung pada class sambungan struktur yang digunakan. Perhitungan menggunakan pendekatan kurva S-N dilakukan untuk mendapatkan nilai $\mathrm{K}_{2}$ yang digunakan sebagai input untuk menghitung nilai cumulative fatigue damage $\mathrm{DM}_{\mathrm{i}}$. Nilai $\mathrm{K}_{2}$ berdasarkan kurva S-N pada CSR ditunjukkan seperti pada Tabel 7.

Tabel 7.

Data Class Sambungan Kurva S-N pada CSR

\begin{tabular}{cccc}
\hline \hline Class & $\mathbf{m}$ & $\mathbf{K}_{\mathbf{2}}$ & $\mathbf{S}_{\mathbf{q}}$ \\
\hline B & 4 & $1.01 \mathrm{E}+15$ & 100.2 \\
C & 3.5 & $4.23 \mathrm{E}+13$ & 78.2 \\
D & 3 & $1.50 \mathrm{E}+12$ & 53.2 \\
E & 3 & $1.04 \mathrm{E}+12$ & 47.0 \\
F & 3 & $6.30 \mathrm{E}+11$ & 39.8 \\
F2 & 3 & $4.30 \mathrm{E}+11$ & 35.0 \\
G & 3 & $2.50 \mathrm{E}+11$ & 29.2 \\
W & 3 & $1.60 \mathrm{E}+11$ & 25.2 \\
\hline \hline
\end{tabular}

Sambungan yang dianalisis dalam penelitian ini termasuk kedalam class $\mathrm{F} 2$, maka nilai $\mathrm{K}_{2}$ yang digunakan adalah $4.3 \times 10^{11}$

\section{G. Cumulative Fatigue Damage}

Setelah melakukan analisis tegangan dan kemudian mengalikan tegangan maksimum dengan faktor konsentrasi tegangan $\mathrm{K}$, maka selanjutnya dilakukan perhitungan akumulasi kerusakan akibat kelelahan (cumulative fatigue damage). Tegangan yang digunakan adalah nilai tegangan maksimum pada tiap kondisi pembebanan karena pada nilai tegangan yang paling tinggi sangat rawan terjadinya retak awal yang dapat berakibat pada retak menjalar.

$$
D M_{i}=\frac{\alpha_{i} N_{L}}{K_{2}} \frac{S_{R i}^{m}}{\left(\ln N_{R}\right)^{m / \xi}} \mu_{i} \Gamma\left(1+\frac{m}{\xi}\right)
$$

Dimana:

$N_{L}=$ jumlah cycle pada umumnya memiliki nilai $0.6 \times 10^{8}$ dan $0.8 \times 10^{8}$ cycles untuk design life 25 tahun

$f_{0}=0.85$, faktor yang diambil dari perhitungan non sailing time for operations seperti saat loading dan unloading, perbaikan, dan lain-lain

$U=0.788 \times 10^{9}$, design life dalam detik untuk design life 25 tahun

$L=$ panjang konstruksi dalam meter

$m=$ parameter kurva $\mathrm{S}-\mathrm{N}$

$K_{2}=$ parameter kurva S-N

$\alpha_{1}=0.5$ untuk kondisi full load

$\alpha_{2}=0.5$ untuk kondisi normal ballast

$S_{R i}=$ stress range pada probabilitas level of $10^{-4}$ dalam $\mathrm{N} / \mathrm{mm}^{2}$

$N_{R}=10000$, jumlah cycle berdasarkan level of $10^{-4}$

$\xi=$ weibull probability distribution parameter
$\Gamma=$ gamma function

$\mu_{i}=$ koefisien diambil dari kurva S-N

$$
\mu_{i}=1-\frac{\left\{r\left(1+\frac{m}{\xi}, v_{i}\right)-v_{i}^{-\Delta m / \xi} \gamma\left(1+\frac{m+\Delta m}{\xi}, v_{i}\right)\right\}}{\Gamma\left(1+\frac{m}{\xi}\right)}
$$

$v_{i}=\left(\frac{S_{q}}{S_{R i}}\right)^{\xi} \ln N_{R}$

$S_{q}=$ nilai tegangan pada intersection kurva S-N dalam $\mathrm{N} / \mathrm{mm}^{2}$

$\Delta m=2$, slope dari kurva S-N

$r(a, x)=$ incomplete gamma function

Tabel 8.

Cumulative Fatigue Damage

\begin{tabular}{ccc}
\hline \hline Kondisi Pembebanan & Sambungan & $\mathrm{DM}_{\mathrm{i}}$ \\
\hline Kondisi 1 & $\begin{array}{c}\text { Bracket dengan } \\
\text { webframe } \\
\text { Kondisi 2 }\end{array}$ & 0.055500961 \\
& Bracket dengan & \\
Kondisi 3 & Bracket dengan & 0.296959750 \\
& webframe & 0.329873761 \\
Kondisi 4 & Bracket dengan & \\
& webframe & 0.183145353 \\
\hline \hline
\end{tabular}

H. Umur Kelelahan (Fatigue Life)

$$
\text { Fatigue life }=\frac{\text { Design life }}{D M} \text { years }
$$

Umur kelelahan yang didapat harus mendekati atau melebihi besar dari design life kapal. Berdasarkan CSR, kriteria design life untuk konstruksi kapal adalah 25 tahun. Dengan menggunakan persamaan tersebut maka akan didapat umur kelelahan dari setiap sambungan struktur untuk tiap kondisi pembebanannya.

Tabel 9.

Fatigue Life Struktur

\begin{tabular}{ccc}
\hline \hline Kondisi Pembebanan & DM $_{\mathrm{i}}$ & $\begin{array}{c}\text { Fatigue Life } \\
\text { (Tahun) }\end{array}$ \\
\hline Kondisi 1 & 0.035969106 & 450 \\
Kondisi 2 & 0.199522899 & 84 \\
Kondisi 3 & 0.222369543 & 76 \\
Kondisi 4 & 0.121330148 & 137 \\
\hline \hline
\end{tabular}

Dari perhitungan umur kelelahan pada Tabel 9. diatas dapat diketahui bahwa umur konstruksi bracket yang terendah terdapat pada kondisi 3 dengan umur kelelahan sebesar 76 tahun. Namun, umur kelelahan tersebut masih memenuhi kriteria yang disyaratkan oleh CSR yaitu lebih dari 25 tahun. 


\section{KESIMPULAN DAN SARAN}

Setelah dilakukan percobaan dan penelitian dari ketiga kondisi pembebanan model maka kesimpulan dari Studi ini adalah sebagai berikut:

1. Lokasi tegangan yang paling tinggi rata-rata terjadi pada sambungan bracket di webframe nomor 4;

2. Nilai umur kelelahan (fatigue life) pada bracket untuk masing-masing kondisi pembebanan, yaitu:

a) Pada kondisi tinggi pengisian muatan $0.3 \mathrm{~h}$ umur kelelahannya adalah 450 tahun

b) Pada kondisi tinggi pengisian muatan $0.6 \mathrm{~h}$ umur kelelahannya adalah 84 tahun

c) Pada kondisi tinggi pengisian muatan $0.7 \mathrm{~h}$ umur kelelahannya adalah 76 tahun

d) Pada kondisi tinggi pengisian muatan $0.95 \mathrm{~h}$ umur kelelahannya adalah 137 tahun

3. Umur kelelahan dapat mencapai 450 tahun dikarenakan asumsi frekuensi yang digunakan adalah frekuensi gerakan kapal tanpa adanya frekuensi sloshing dalam tangki dan tekanan hidrostatik gelombang;

4. Fatigue life struktur yang dianalisa memenuhi persyaratan CSR yaitu lebih dari 25 tahun.

Beberapa hal yang dapat disajikan sebagai saran pada penelitian ini adalah sebagai berikut:

1. Pada penelitian ini digunakan pembebanan lokal statis muatan. Namun pada kondisi sebenarnya terjadi berbagai macam pembebanan yang dialami struktur konstruksi kapal. Untuk mendapatkan hasil yang lebih valid dan akurat maka penelitian ini dapat dikembangkan dengan menambah pembebanan dinamis.

2. Perlu dilakukan pemeriksaan UT (ultrasonic) berkala untuk mengetahui laju pengurangan pelat pertahun sehingga tebaal pelat kapal yang digunakan sebagai input adalah tebal pelat kapal terbaru.

\section{UCAPAN TERIMAKASIH}

Penulis mengucapkan terima kasih kepada semua pihak yang terkait dengan penelitian ini.

\section{DAFTAR PUSTAKA}

\& J. M. C. G.E. Horn, Y.K. Chen, Safehull Fatigue Assessment of Ship Structural Details. New York: American Bureau of Shipping, 1999.

[2] P. Kurnianto, "Perkiraan Umur Konstruksi FPSO Konversi dari Tanker dengan Analisis Fatigue," Institut Teknologi Sepuluh Nopember, 2012.

[3] D. Septiana, "Perkiraan Fatigue Life pada Bracket Kapal Tanker Berdasarkan Common Structural Rules," Institut Teknologi Sepuluh Nopember, 2012.

[4] M. A. Syaiful, "Simulasi Sloshing pada Dinding Tanki Tipe Membran Kapal LNG Akibat Gerakan Heaving dan Pitching di Gelombang Reguler,” Institut Teknologi Sepuluh Nopember, 2013.

[5] IACS, Common Structural Rules for Double Hull Oil Tankers. Italy: RINA, 2014.

[6] K. P. Owen, F. H., \& Jeom, Ship Structural Analysis and Design. New Jersey: The Society of Naval Architects and Marine Enginner, 2010. 